\title{
Hybrid Renewable Energy Systems for Electrification: A Review
}

\author{
Ibrahim Baba Kyari', *, Jamilu Ya'u Muhammad ${ }^{2}$ \\ ${ }^{1}$ Department of Electrical and Electronics Engineering, Usman Danfodiyo University, Sokoto, Nigeria \\ ${ }^{2}$ Department of Mechanical Engineering, Bayero University, Kano, Nigeria
}

Email address:

jamiluuk87@outlook.com (I. B. Kyari)

${ }^{*}$ Corresponding author

\section{To cite this article:}

Ibrahim Baba Kyari, Jamilu Ya'u Muhammad. Hybrid Renewable Energy Systems for Electrification: A Review. Science Journal of Circuits, Systems and Signal Processing. Vol. 8, No. 2, 2019, pp. 32-39. doi: 10.11648/j.cssp.20190802.11

Received: July 8, 2019; Accepted: July 29, 2019; Published: August 14, 2019

\begin{abstract}
Renewable energy systems are becoming widespread in the future due to adverse environmental friendly and abundant in nature. Solar and wind energy resources are alternative to each other which will have the actual potential to satisfy the energy demand. But wind energy system may not be technically viable at all sites because of low wind speeds and being more unpredictable than solar energy. Due to this reason a combined utilization of these renewable energy sources are therefore becoming increasingly attractive and are being widely used as alternative of oil-produced energy and this is called "Hybrid Renewable Energy Systems. These hybrid energy systems are becoming popular in remote area power generation applications due to advancements in renewable energy technologies and substantial rise in prices of fossil fuel. This paper presents an extensive review on hybrid renewable energy systems configurations, mathematical modeling and control strategies of the system. This Paper also highlights the optimization techniques which have the potential to increase the economic attractiveness of the system.
\end{abstract}

Keywords: Hybrid System, HOMER, MATLAB, Remote Area Power Supply (RAPS), Solar PV, Wind Turbine

\section{Introduction}

With rapid growth on fossil fuel scarcity and environmental concern such as global warming and pollution in a world of today, the renewable energy such as solar, wind, biomass, and micro-hydro systems can be seen as suitable alternatives to conventional power due to their sustainable behaviour. Also, solar energy and wind energy studies are limited due to location and weather change, therefore a new development was discovered that can generate electricity without limitation especially in a rural area, this new development is hybrid system that consists of different renewable sources integrated as one power plant. The solar $\mathrm{PV}$ and Wind energy sources have been proved as more promising, technically matured, and cost effective energy sources. They are being used in many places of world as a single source is combined as hybrid power system [1-4].

The solar PV system is powered by the solar energy which is abundantly available in nature. The solar-generated electricity is called Photovoltaic (or PV). Photovoltaic are solar cells that convert sunlight to D.C electricity. These solar cells in solar PV module are made from semiconductor materials. When light energy strikes the cell, electrons are emitted. The electrical conductor attached to the positive and negative scales of the material allow the electrons to be captured in the form of a D.C current. The generated electricity can be used to power a load or can be stored in a battery. Photovoltaic system is classified into two major types: the off-grid (stand-alone) systems and inter-tied system. The off-grid (stand-alone) systems are mostly used where there is no utility grid service. It is very economical in providing electricity at remote locations especially rural banking, hospital and ICT in rural environments. Solar PV systems generally can be much cheaper than installing power lines and step-down transformers especially to remote areas. Solar modules produce electricity devoid of pollution, without odor, combustion, noise and vibration. Hence, unwanted nuisance is completely eliminated. Also, unlike the other power supply systems which require professional training for installation expertise, there are no moving parts or special repairs that require such expertise [5]. 
Wind Power is energy extracted from the wind, passing through a machine known as the windmill. Electrical energy can be generated from the wind energy. This is done by using the energy from wind to run a windmill, which in turn drives a generator to produce electricity [6]. The windmill in this case is usually called a wind turbine. This turbine transforms the wind energy to mechanical energy, which in a generator is converted to electrical power. An integration of wind generator, wind turbine, aero generators is known as a wind energy conversion system (WECS) [7].

\section{Hybrid Renewable Energy System and Their Classifications}

Hybrid power systems can be designed based on the following technical topologies to extract the available renewable energy sources and to meet the required load. This can be arranged in different ways with the voltage and the load demand as the determinant factors. According to Sengprasong et al. [8] any power system configurations are classified in the following grouped:

\subsection{AC/DC-Coupled Hybrid Power Systems}

Hybrid power systems can be classified according to the voltage and the load demand they are coupled with into four configurations.

\subsubsection{AC-Coupled Hybrid Power Systems}

Here, all the energy generating components or units and the energy storage technologies are connected to the $\mathrm{AC}$ bus in line with the load or directly to the load. This type of power system setup could also subdivide into centralized and decentralized configuration systems.

A. Centralized AC-coupled hybrid system: All the components are connected to the AC line. AC Electricity generating components could connect directly to $\mathrm{AC}$ line or may require $\mathrm{AC} / \mathrm{AC}$ converter to get stable component coupling topology. The master inverter helps to control the energy flow to the battery and out of the battery to the load. Furthermore DC electricity can be provided from battery if needed.

B. Decentralized AC-coupled hybrid system: In this type, all the technologies are not connected to any of the bus; rather they individually connect to the load directly. By comparing the two configurations the centralized system is better due to its controllability than the distributed system [10].

\subsubsection{DC-Coupled Configuration}

In the direct current (DC) combination all the energy conversion systems are connected to the main DC bus before connected to the AC load side. All AC power sources are converted into DC power sources then connected to the AC load consumer using a relevant converter. Such combinations are used in solar PV home systems up to a certain size of $\mathrm{kW}$ [8]. Home system energy providers can be supported with inverters to provide AC load as needed. Single home system power suppliers are combined with other generating units/systems when large amount of energy is sought. The added energy generating units are normally wind energy and diesel generator.

\subsection{Series/Parallel Hybrid Power System}

Hybrid power systems are also classified into two basic configurations based on how load is provided from renewable energy conversion systems and diesel generator [10]. Series hybrid and parallel hybrid power systems are the two configurations and their detail discussions is given as follows.

\subsubsection{Series Hybrid Power System}

The power generated from all the energy generating components is supplied to charge the battery bank before sending to the individuals load demand. Each of the power generating components is engaged with power converter. Charge controller is used to prevent the overcharging and under-discharging of the battery. In series hybrid system, all the power generating units and storage system are connected to DC-bus. Furthermore it can also be named as centralized DC-bus topology. The AC power producing components has to be attached to the DC line using rectifier [9].

\subsubsection{Parallel Hybrid Power System}

In the case of Parallel hybrid systems configuration, the $\mathrm{AC}$ producing power components like wind turbine and diesel generator can provide part of the load directly to consumers. It has somehow complex design, but it has advantage as compared with series arrangement, optimal power generation can be met, maximized diesel efficiency, possible decrease in capacity of fuel and battery. The DC-coupling configuration uses bi-directional inverter which can act as inverter for diesel generator and rectifier for battery charging, this is in a sense that renewable energy generating units are connected to DC bus then supply AC load through the bi-directional inverter. The AC-coupled and DC-coupled configurations are the two sub-configurations of the parallel hybrid power system. The $\mathrm{AC}$ power from wind turbine should be converted to $\mathrm{DC}$ through AC/DC converters before sending to the battery bank. The DC coupled hybrid power system can be improved via linking the renewable generators to the $\mathrm{AC}$ bus to form an $\mathrm{AC}$ coupling configuration. The power from the generator set and renewable energy can be provided in parallel to the consumers. Bidirectional inverter is used for the sake of either the battery can be charged or supply the load depending upon the load and the status of energy sources [9].

\section{Modeling of Components of Hybrid Renewable Energy System}

The hybrid renewable energy system consists of solar array (PV) system, wind energy system and diesel generator and battery storage system as an integrated system. The block diagram of the hybrid renewable energy system is illustrated in the figure 1 below: 


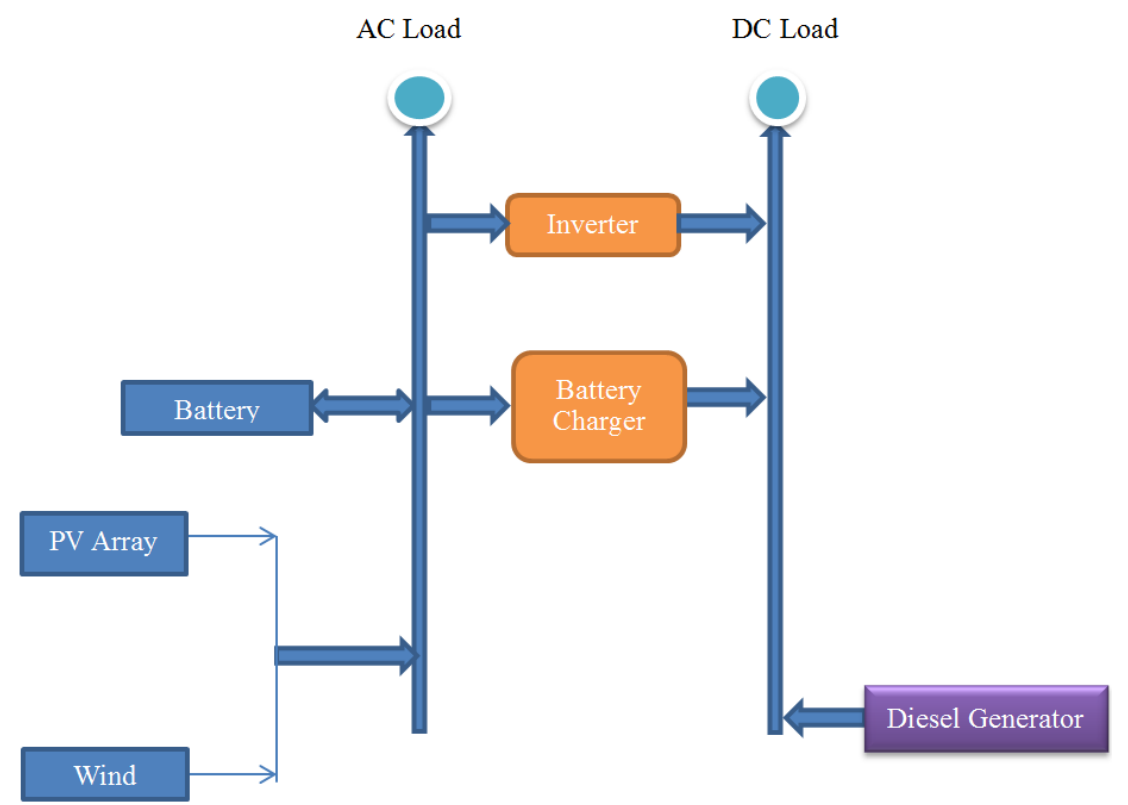

Figure 1. Block Diagram of Hybrid Renewable Energy System.

\subsection{Modeling of PV Cell}

The photovoltaic system converts sunlight directly to electricity without having any disastrous effect on our environment. The basic segment of PV array is PV cell, which is just a simple p-n junction device. Equivalent circuit has a current source (photocurrent), a diode parallel to it, a resistor in series describing an internal resistance to the flow of current and a shunt resistance which expresses a leakage current. The current supplied to the load can be given by Sandeep [11].

$$
I=I_{P V}-I_{o}\left[\exp \left(\frac{V+I R_{S}}{a V_{T}}\right)-1\right]-\left(\frac{V+I R_{S}}{R_{p}}\right)
$$

Where: $I_{P V}$ is photocurrent; $I_{0}$ is a diode's reverse saturation current; $\mathrm{V}$ is a voltage across the diode; $\mathrm{R}_{\mathrm{s}}$ is a series resistance; $a$ is an ideality factor; $\mathrm{V}_{\mathrm{T}}$ is a thermal voltage and $R_{p}$ is a shunt resistance.

PV cell photocurrent, which depends on the radiation and temperature, can be expressed as:

$$
I_{P V}=\left(I_{P V-S T C}+K_{I} \Delta T\right) \frac{G}{G_{S T C}}
$$

Where: $\mathrm{I}_{\mathrm{PV}-\mathrm{STC}}$ is a light generated current under standard test condition; $\mathrm{K}_{\mathrm{I}}$ is a cell's short circuit current temperature coefficient; $\Delta \mathrm{T}$ is a change in temperature; $\mathrm{G}$ is a solar irradiation and $\mathrm{G}_{\mathrm{STC}}$ is a nominal solar irradiation.

The reverse saturation current varies as a cubic function of temperature, which is represented as:

$$
I_{o}=I_{o-S T C}\left(\frac{T_{S T C}}{T}\right)^{3} \exp \left[\frac{q E_{g}}{a K}\left(\frac{1}{T_{S T C}}-\frac{1}{T}\right)\right]
$$

Where: $\mathrm{I}_{\mathrm{o}-\mathrm{STC}}$ is a nominal saturation current; $\mathrm{q}$ is a charge of electron; $\mathrm{T}_{\mathrm{STC}}$ is a saturation temperature and $\mathrm{E}_{\mathrm{g}}$ is an energy band gap of semi-conductor.

\subsection{Modeling of Wind Energy System}

The mathematical modeling of wind energy conversion process comprises wind turbine dynamics and generator modeling. Power generation through the wind turbine can be calculated by wind power equation. Bhave [12] estimates the generated output power and torque by the wind turbine by giving the formula.

$$
P_{T}=1 / 2\left(C_{p} \lambda_{p} A V^{3}\right)
$$

Where: $\mathrm{P}_{\mathrm{T}}$ is an output power; $\mathrm{C}_{\mathrm{p}}$ is a power coefficient; $\lambda_{\mathrm{p}}$ is a tip speed ratio; $\mathrm{A}$ is a frontal area of the wind turbine and $\mathrm{V}$ is a wind speed.

Torque developed by wind turbine given as

$$
T_{T}=\frac{P_{T}}{\omega M}
$$

Where: $T_{\mathrm{T}}$ is a torque developed by wind turbine and $\omega$ is a turbine rotor speed

And the tip speed ratio of the wind turbine can be obtained using equation:

$$
\lambda_{p}=\frac{\omega R}{V}
$$

Where: $\mathrm{R}$ is a radius of the turbine blade

$\mathrm{C}_{\mathrm{P}}$ can be expressed as the function of the tip-speed ratio (

$$
C_{p}=1 / 2\left(\frac{116}{\lambda_{1}}-0.4 \beta-5\right) \exp \frac{-16.5}{\lambda_{1}}
$$

Where:

$$
\lambda_{1}=\left[\frac{1}{\frac{1}{\lambda+0.089}-\frac{0.035}{\beta^{3}+1}}\right]
$$




\section{Controls of Hybrid Renewable Energy System}

Since the hybrid renewable energy system combined different renewable energy sources, it is difficult to the system to be efficient and reliable without applying any proper control strategy [13]. The objectives of the control of a hybrid renewable energy system are to maintain the state of charge of the battery bank to prevent blackout; to extend the life of the batteries and to satisfy the changeable load power demand. For these reasons, different researchers present their views in different locations and some are discussed as follows:

Hancock et al. [14] presents a method for optimizing and controlling the operation of stand-alone hybrid power systems with consists of solar PV, generator and storage battery. The authors developed and analyzed a method for optimizing the operation of hybrid remote area power supply (RAP) systems.

A control strategy for a wind energy conversion scheme using induction generators was designed by Abdin and $\mathrm{Xu}$ [15]. The scheme consists of a three-phase induction generator driven by a horizontal axis wind turbine and interfaced to the utility through a double overhead transmission line. A static VAR compensator was connected at the induction generator terminals to regulate its voltage. The mechanical power input was controlled using the blade pitch-angle. Both state and output feedback controllers are designed using MATLAB software to regulate the generator output. The results revealed that the response of closed loop system exhibited a good damping and fast recovery under different type of large disturbances.

El-Shater et al. [16] discussed the Energy flow and management of a hybrid wind/PV/fuel. The energy system combined solar PV, wind and fuel cells and each of the three energy sources is controlled so as to deliver energy at optimum efficiency. Fuzzy logic control technique was employed to achieve maximum power tracking for both PV and wind energies and to deliver this maximum power to a fixed DC voltage bus.

A solution to the short term generation scheduling problem in a hybrid energy system was developed by Fung et al. [17] used in remote area power supply (RAPS). Instead of extending the main electricity grid, RAPS systems are economical alternatives for the supply of electrical energy to consumers in remote areas. They proposed a new approach based on fuzzy-logic (FL) and genetic algorithm (GA) techniques for the scheduling of the battery and the diesel generator of a RAPS system [18]. They also have developed two methods. One was based on a pure genetic algorithm (PGA) approach, and the other was based on a combined fuzzy-logic and genetic algorithm (FGA). Park et al. [19] presented the power compensation system for controlling energy flow through hybrid energy system according to load demand.

Das et al. [20] proposes modeling of solar PV/wind/fuel cell hybrid energy system. In worst environmental conditions, when there is no output power from the wind or photovoltaic sources, the fuel cell will operate at its rated power of $10 \mathrm{~kW}$. They proposed a simple and economic control method with DC-DC converter is used for maximum power point tracking and hence maximum power extraction from the wind turbine and photovoltaic array. The individual DC-DC converters are in turn connected to a single PWM voltage source inverter, which holds the output voltages of all the converters at a fixed value by balancing input and output power of the DC links. All the energy sources are modeled using PSIM software tool to analyze their dynamic behavior. The complete hybrid system is simulated for different operating conditions of the energy sources.

Bansal et al. [21] discussed an automatic reactive-power control of an isolated wind-diesel hybrid power system having an induction generator (IG) for a wind-energy conversion system and synchronous generator (SG) for a diesel generator (DG) set.

The wind turbine was controlled by a pitch angle controller and a solar PV electricity generation unit was controlled by a maximum power point tracking (MPPT) controller as the control strategy for a hybrid renewable energy system; furthermore, dynamic models have been used for all the components of the system [22].

Li et al. [23] introduces the hardware realization of the energy management and control subsystem of a gridconnected wind/solar hybrid power system. The system is composed of several modules: programmable logic controller (FBs-40MAT from FATEK), AC multi-function electric power meters, Grid-connection control module, humanmachine interface (HMI), DC electric power meters, and RS485/TCP converter to control and manage the operation of multi-source.

\section{Optimization Techniques of Hybrid Renewable Energy System}

The accurate sizing of every system component is critical for the techno-economic assessment of the whole system. Various optimization techniques such as linear programming, dynamic programming, probabilistic approach, iterative technique, and multi-objective genetic algorithm were used by researchers to design hybrid energy system in a most cost effective way.

Barton and Infield [24] have considered the possibility of increasing renewable generation and energy storage on weak electricity grids. Specifically, the investment criterion in their model was based on capital deferral for transmission lines. They found that storage options over long periods (i.e. 24hours) with redox flow cells were able to allow $25 \%$ more of the wind energy to be absorbed without grid reinforcement but were not economically viable. Conversely, short term storage using flywheels allowed 10\% more of the wind energy to be absorbed and provided significant economic benefits to the electricity system.

Zoulias and Lymberopoulos [25] have provided a techno- 
economic comparison of an existing hybrid stand-alone power system and hydrogen based power system. They found that, while it is technically feasible to replace fossil fuel based generator sets with hydrogen-based systems, it requires a $50 \%$ cost reduction on electrolysers and $40 \%$ on hydrogen tanks to be economical. They also stressed the importance of sizing and found that generator sets and battery banks can be replaced with fuel cells by oversizing the renewable energy system (PV array in this study).

Abbey et al. [26] proposed an analysis of stand-alone power systems with wind generation and energy storage. They found that, at current storage prices, there is an economic benefit to install energy storage when the wind penetration reaches 60 to $80 \%$ of the power demand, and the economic benefit starts decreasing beyond $80 \%$.

Nottrott et al. [27] have used LP under MATLAB to model the optimal storage dispatch schedules for peak load management and demand charge minimization in a gridconnected system combining battery and PV. They found that the net present values (NPV) of the battery system and battery lifetime were significantly improved with the forecasting of time of use (ToU) prices. However, their results ultimately showed that Lithium-Ion batteries are a financially viable option - in demand side applications at an installed cost of $\$ 400-\$ 500$ per $\mathrm{kWh}$ of capacity, which represented around $40-50 \%$ of 2011 's price level.

Mohammad et al. [28] have developed the numerical power pinch analysis in order to consider the energy losses of hybrid power systems. The authors argued that different types of appliances use different type of power; for instance, some appliances are AC and others are DC. As a result, they proposed that the application of their methodology can avoid unnecessary power conversion and reduce the optimal storage capacity in hybrid power systems.

Kazempour et al. [29] have developed a self-scheduling approach under GAMS for the operation of $\mathrm{NaS}$ batteries and pumped storage plants with considerations for the nonlinearity of maintenance cost and storage efficiency. They found that the internal rate of return (IRR) was 29\% for pumped-hydro, and $17 \%$ for NaS battery plants.

Kongnam et al. [30] have used mixed integer nonlinear programming to determine the optimum generation capacity of wind farms, with the aim of maximizing profit-to-cost and profit-to-area ratios. The optimization problem was formulated in order to select the optimal technological type and size with regard to operation costs, maintenance costs, and available area. Nonlinear elements of wind turbine operations such as cut-in and cut-out wind speed were considered in the model. Weibull and Ryleigh distributions were used to model the wind speed uncertainty, using hourly data at Phuket wind station in Thailand. As a result, they found that the NPV of wind turbines was associated with both investment capacity and turbine sizes.

Wang and Singh [31] have applied a fuzzified multiobjective particle swarm optimization algorithm to investigate the optimal generation dispatch in electric power systems. Both aggregated function and Pareto-based methods were used to determine the best power configuration of generators, including costs and emissions as objective functions.

Tsung-Ying [32] proposed a multi-pass iteration particle swarm optimization algorithm (MIPSO) to determine the optimal dispatch power of a battery storage system and wind turbine generators for a time-of-use rate industrial user. Weibull probability density functions were generated with the software HOMER to assess wind speed probability. As a result, they suggested that higher profits can be generated by accounting for load uncertainties.

Lee and Chen [33] have applied the evolutionary particle swarm optimization (EPSO) technique to investigate the optimal contract capacities and installed capacities of a wind and PV generation system for time-of-use rate industrial user. The program HOMER was used to generate wind speed probabilities using a Weibull distribution. They suggested that the most critical influencing factor of the benefit-cost ratio was the energy cost while the capital cost had the greatest influence on the optimal installed capacity.

Li et al. [34] have explored a novel hybrid system including hydrogen fuel cell for long-term storage and battery banks for short-term storage. Based on DP, they have determined the optimal system configuration with regard to system costs and system efficiency. On the economic side, they measured the cost/benefit potential of the different systems, including fixed costs, variables costs, and levelized cost of electricity. On the engineering side, the study applied three different efficiency metrics, including total system efficiency, loss efficiency (i.e. dump load), and used efficiency (i.e. actual efficiency). Their results suggested that coupling hydrogen and battery storage enables higher system efficiencies and lower costs than traditional off-grid systems.

Korpaas et al. [35] have applied a DP algorithm for the scheduling and operation of energy storage for wind power plants. Wind forecasting was used to determine the next day storage capacity. As a result, they suggested that energy storage can increase financial revenues by taking advantage of price fluctuations. However, electrochemical energy storage was found to be more expensive than grid reinforcement. It was also proposed that energy storage can be more advantageous where grid extensions would lead to adverse consequences on the local environment.

Kaldellis et al. [36] have used a similar iterative approach to assess the payback of stand-alone hybrid energy systems, including solar photovoltaic (PV) and battery storage. As expected, they found that local solar conditions are a remarkable influencing factor of life cycle costs. Interestingly, they proposed that battery storage exceeded $27 \%$ of their system costs, which emphasized the difference between stand-alone and grid-connected systems.

According to the study conducted by Himri et al. [37] which was devoted to the study of techno-economic aspects of hybrid (wind and diesel generator) schemes for a rural community in Algeria. The study was conducted to add a wind turbine to existing diesel power plant systems to reduce 
fuel consumption. The author concluded for wind speed below $5 \mathrm{~m} / \mathrm{s}$ the existing diesel operated plant with 0.05 $0.179 \$ /$ liter is cost efficient than the hybrid system. The feasibility of the hybrid system assured at wind speed of 5.48 $\mathrm{m} / \mathrm{s}$, maximum annual capacity shortage $0 \%$, minimum renewable fraction $0 \%$ and $\$ 0.162 /$ liter fuel price.

A research carried by Boneya [38] described the design information of solar photovoltaic (PV) and wind turbine hybrid power generation system to provide electricity to a model community of 100 households and health clinic and elementary school. The optimal simulation result showed that $\mathrm{PV} /$ wind turbine/diesel generator/battery and convertor configured system. For this configuration the total NPC and $\mathrm{COE}$ is $\$ 103,914$ and $0.302 \$ / \mathrm{kWh}$ respectively, for a renewable fraction of $84 \%$, and diesel fuel consumed is 1,955 liters per annum accordingly it runs for 633 hours per year.

According to Nfah, et al. [39] simulation of a standalone electricity production for the remote settlements in Cameron was conducted. The study also presented the energy requirement in rural villages is basically for lighting, radio and television entertainments. They simulated and modeled four different system configurations such as; (hydro-LPG generator-battery), (solar-LPG generator-battery), (micro hydro-diesel generator-battery), (solar-diesel-battery). From the simulation result the cost of energy for different renewable energy option was found to be $0.296 € / \mathrm{kWh}$ for micro hydro hybrid system generated from a $14 \mathrm{~kW}$ micro hydro generator, $15 \mathrm{~kW} \mathrm{LPG} \mathrm{generator} \mathrm{and} 36 \mathrm{kWh}$ of battery storage. Furthermore, the second simulation for PV hybrid system was accounted for $18 \mathrm{~kW}$ PV generator, 15 $\mathrm{kW}$ LPG generator and $72 \mathrm{kWh}$ of battery storage, the cost of energy was obtained as $0.576 € / \mathrm{kWh}$ for remote petrol price of $0.1 € /$ litter and LPG price of $0.7 € / \mathrm{m}^{3}$. The micro hydro system proved to be the cheapest option for the southern parts of Cameroon at a minimum flow rate of 200 liter/second, while the photovoltaic (PV) hybrid was the cheapest in the southern parts of the country.

$\mathrm{Ai}$, et al. [40] has presented a complete set of mathematic calculation methods for optimum sizing of solar PV/wind hybrid system. In this method, the more accurate and practical mathematic models for characterizing solar photovoltaic (PV) module, wind generator and battery are adopted; combining with hourly measured meteorological data and load data, the performance of a solar PV/wind hybrid system was determined on hourly basis; by fixing the capacity of wind generators, the whole year's LPSP (loss of power supply probability) values of solar PV/wind hybrid systems with different capacity of solar photovoltaic (PV) array and battery bank are calculated, then the trade-off curve between battery bank and solar photovoltaic (PV) array capacity is drawn for the given LPSP value; the optimum configuration which can meet the energy demand with the minimum cost can be found by drawing a tangent to the tradeoff curve with the slope representing the relationship between cost of solar photovoltaic (PV) module and that of the battery [41].
Shahirinail, et al. (2006) compared results of two optimization techniques based on simplex and other algorithm for hybrid PV/wind energy system. They presented a method for assessment on the basis of loss of load probability (LOLP) to decide an optimal proportion of solar photovoltaic (PV) and wind generator capacities in hybrid solar PV/wind energy system; optimal system combination was selected on the basis of capital cost and annual autonomy level.

\section{Conclusions}

After reviewing different work done in hybrid energy system, the following conclusion remarks were drawn-out:

a) The hybrid energy systems are recognized as a viable alternative to grid supply or conventional, fuel-based, remote area power supplies all over the world.

b) Some authors have suggested that heuristic methods can offer shorter computational time than dynamic programming especially when stochastic parameters are included [32].

c) There is a need for further research and development (R\&D) improvements in solar photovoltaic (PV) and wind technologies that can reduce the cost of hybrid system.

d) Since there is abundant wind energy source in an island, therefore, there is need for combining wind/solar hybrid system with hydro power generation system.

e) There is a need to carry out transient analysis of the system for varying constraint like solar radiation, wind velocity, load demand.

\section{References}

[1] Skretas, S. B.; Papadopoulos D. P. (2009). Efficient design and simulation of an expandable hybrid (wind-photovoltaic) power system with MPPT and inverter input voltage regulation features in compliance with electric grid requirements. Electric Power Systems Research, 79 (9): 12711285 .

[2] Kalantar, M.; Mousavi G. S. M. (2010). Dynamic behavior of a stand-alone hybrid power generation system of wind turbine, micro-turbine, solar array and battery storage. Applied Energy, 87 (10): 3051-3064.

[3] Dursun, E.; Kilic, O. (2012). Comparative evaluation of different power management strategies of a stand-alone PV/Wind/PEMFC hybrid power system. Electrical Power and Energy Systems, 34 (1): 81-89.

[4] Bhende, C. N.; Mishra, S.; Malla, S. M. (2011). Permanent Magnet Synchronous Generator-Based Stand-alone Wind Energy Supply System. IEEE Transactions on Sustainable Energy, 2 (4): 361-373.

[5] Olajide, M. B.; Oni, J. O. (2009). Application of Solar Energy for offices and homes, Workshop Seminar Paper, International Training School and Workshop on Solar Energy, organized at University of Agriculture, Abeokuta, $9^{\text {th }}-11^{\text {st }}$ June, 18-29.

[6] Technical brief on Wind Electricity Generation (2009): Retrieved on May 25, 2019, from www.windpower.org 
[7] Iheonu, E. E.; Akingbade, F. O. A.; Ocholi, M. (2002). Wind Resources Variations over selected sites in the West African sub-region. Nigerian Journal of Renewable Energy, 10, 43-47.

[8] Sengprasong, P.; Jean-Yves L. C.; Demba, D.; Ghislain, R.; Claude M. (2010). Reviews on Micro-Grid Configuration and Dedicated Hybrid System Optimization Software Tools: Application to Laos. Engineering Journal, 14 (3): 15-34.

[9] Solomon, T. B. (2013). Design and analyzing of an off-grid hybrid renewable energy system for rural electrification in Ethiopia. Master's Thesis, Division of Heat and Power Technology, KTH, School of Industrial Engineering and Management, Sweden.

[10] Weldemariam, L. E. (2010). Gen-Set/Solar/Wind Hybrid Power System of Off-Grid Power Station for Rural Applications. PhD thesis, Department of Electrical Power Engineering, Delft University of Technology, Delft, The Netherlands.

[11] Sandeep, K. (2015). Modeling and simulation of hybrid wind/PV stand-alone generation system. Master's thesis, Department of Electrical Engineering, National Institute of Technology, Rourkela.

[12] Bhave, A. G. (1999). Hybrid solar-wind domestic power generating system-case study. Renewable Energy, 17, 355358 .

[13] Dimeas, A. L.; Hatziargyriou, N. D. (2005). Operation of a multi-agent system for micro-grid control. IEEE Transactions on Power Systems, 20, 1447-1455.

[14] Hancock, M.; Outhred, H. R.; Kaye, R. J. (1994). A new method for optimization the operation of stand-alone PV hybrid power systems. In: 1994 IEEE First WCPEC. 1188-1191.

[15] Abdin, S.; Xu, W. (1998). Control design and dynamic performance analysis of a wind turbine-induction generator unit. IEEE Conference 1998; 1198-1205.

[16] El-Shater, T. F.; Eskander, M.; El-Hagry, M. (2001). Hybrid $\mathrm{PV} /$ fuel cell system design and simulation. In: 36th intersociety energy conversion engineering conference; 112 121.

[17] Fung, C. C.; Rattanongphisat, W.; Nayar, C. (2002). A simulation study on the economic aspects of hybrid energy systems for Remote Islands in Thailand. IEEE Transaction; 8: $25-32$.

[18] Chedid, R. B.; Karaki, S. H.; El-Chamali, C. (2000). Adaptive fuzzy control for wind-diesel weak power system. IEEE Transactions on Energy Conversion; 15 (1): 71-78.

[19] Park, S. J.; Kang, B. B.; Yoon, J. P.; Cha, I. S.; Lim, J. Y. (2004). A study on the stand-alone operating or photovoltaic wind power hybrid generation system. $35^{\text {th }}$ annual IEEE power electronics specialist conference; 2095-2099.

[20] Das, D.; Esmaili, R.; Dave Nichols, L. X. (2005). An optimal design of a grid connected hybrid wind/photovoltaic/fuel cell system for distributed energy production. IEEE Transaction; 23 (5): 2499-2505.

[21] Bansal, R. C.; Bhatti, T. S.; Kothari, D. P. (2003). Automatic reactive power control of wind/diesel/ micro-hydro autonomous hybrid power systems using ANN tuned static var Compensator. IEEE Transaction; 14 (3): 182-188.
[22] Wang, C.; Nehrir, M. H. (2008). Power management of a stand-alone wind/photovoltaic/fuel cell energy system, IEEE Transaction on Energy Conversion, 23 (3), 957-967.

[23] Li, G.; Chen, Y.; Li, T. (2009). The realization of control subsystem in the energy management of wind/solar hybrid power system. Power Electronics Systems and Applications, China. 1-4.

[24] Barton, J. P.; Infield, D. G. (2004). Energy storage and its use with intermittent renewable energy. IEEE Transactions on Energy Conversion, 19 (2), 441-448.

[25] Zoulias, E. I.; Lymberopoulos, N. (2007). Techno-economic analysis of the integration of hydrogen energy technologies in renewable energy-based stand-alone power systems. Renewable Energy, 32 (4), 680-696.

[26] Abbey, C.; Robinson, J.; Joos, G. (2008). Integrating renewable energy sources and storage into isolated diesel generator supplied electric power systems. IEEE, pp. 21782183 .

[27] Nottrott, A.; Kleissl, J.; Washom, B. (2013). Energy dispatch schedule optimization and cost benefit analysis for gridconnected, photovoltaic-battery storage systems. Renewable Energy, 55, 230-240.

[28] Mohammad R.; Wan Alwi, N. E.; Abdul Manan, S. R.; Klemes, Z.; Hassan, M. Y. (2013). Process integration of hybrid power systems with energy losses considerations. Energy.

[29] Kazempour, S. J.; Moghaddam, M. P.; Haghifam, M. R.; Yousefi, G. R. (2009). Electric energy storage systems in a market-based economy: Comparison of emerging and traditional technologies. Renewable Energy, 34 (12), 2630-2639.

[30] Kongnam, C.; Nuchprayoon, S.; Premrudeepreechacharn, S.; Uatrongjit, S. (2009). Decision analysis on generation capacity of a wind park. Renewable and Sustainable Energy Reviews, 13 (8), 2126-2133.

[31] Wang, L.; Singh, C. (2007). Environmental/economic power dispatch using a fuzzified multi-objective particle swarm optimization algorithm. Electric Power Systems Research, 77 (12), 1654-1664.

[32] Tsung-Ying, L. (2007). Operating schedule of battery energy storage system in a time-of use rate industrial user with wind turbine generators: A multi-pass iteration particle swarm optimization approach. IEEE Transactions on Energy Conversion, 22 (3), 774-782.

[33] Lee, T. Y.; Chen, C. L. (2009). Wind-photovoltaic capacity coordination for a time-of use rate industrial user. Renewable Power Generation, IET, 3 (2), 152-167.

[34] Li, C. H.; Zhu, X. J.; Cao, G. Y.; Sui, S.; Hu, M. R. (2009). Dynamic modeling and sizing optimization of stand-alone photovoltaic power systems using hybrid energy storage technology. Renewable Energy, 34 (3), 815-826.

[35] Korpaas, M.; Holen, A. T.; Hildrum, R. (2003). Operation and sizing of energy storage for wind power plants in a market system. International Journal of Electrical Power and Energy Systems, 25 (8), 599-606.

[36] Kaldellis, J.; Zafirakis, D.; Kondili, E.; (2009). Optimum autonomous stand-alone photovoltaic system design on the basis of energy pay-back analysis. Energy, 34 (9), 1187-1198. 
[37] Himri, Y.; Boudghene, A. S.; Draoui, B.; Himri, S. (2008). Techno-Economical Study of Hybrid Power System for a Remote Village in Algeria. Energy, 33 (7): 1128-1136.

[38] Boneya, G. (2011). Design of a Photovoltaic-Wind Hybrid Power Generation System for Ethiopian Remote area, PhD thesis, Institute of Technology Department of Electrical and Computer Engineering, Addis Ababa University.

[39] Nfah, E. M.; Ngundam, J. M.; Vandenbergh, M.; Schmid, J. (2008). Simulation of Off-Grid Generation Options for Remote Villages in Cameroon. Renewable Energy, 33 (5): 1064-1072.
[40] Ai, B.; Yang, H.; Shen, H.; Liao, X. (2003). Computer-aided design of PV/wind hybrid system. Renewable Energy; 28 (10): $1491-1512$.

[41] Buckeridge, J. S.; Ding, J. J. (2000). Design considerations for a sustainable hybrid energy system. IPENZ Transactions; 27 (1): $1-5$.

[42] Shahirinial, A. H.; Tafreshi, S. M. M.; Hajizadeh, A.; Gastaj; Moghaddamj, A. R. (2006). Optimal sizing of hybrid power system using genetic algorithm. IEEE Transaction; 11: 212218. 